\title{
Application of Pressure-Derived Myocardial Fractional Flow Reserve in Assessing the Functional Severity of Coronary Artery Stenosis in Patients With Diabetes Mellitus
}

\author{
Hidefumi Yanagisawa, MD; Taishiro Chikamori, MD; Nobuhiro Tanaka, MD; \\ Yasuhiro Usui, MD; Kenji Takazawa, MD; Akira Yamashina, MD
}

\begin{abstract}
Background Although the development of a coronary guidewire mounted with a pressure sensor has facilitated the measurement of pressure-derived fractional flow reserve (FFR) to assess the functional severity of coronary artery stenoses, the theoretical limitations include diabetes mellitus because of the associated microvascular abnormalities.

Methods and Results In the present study 304 vessels and their coronary territories in 96 diabetic and 149 nondiabetic patients were evaluated by pressure-derived FFR and thallium-201 single photon emission computed tomography (SPECT) to determine the applicability of measuring FFR in diabetic subjects. The best cut-off value for FFR to detect myocardial ischemia, as demonstrated by ${ }^{201} \mathrm{Tl}$ SPECT, was 0.725 in the diabetic and 0.745 in the nondiabetic patients. Sensitivity and specificity were similar for the 2 groups $(83 \%$ and $75 \%$ (diabetic) vs $79 \%$ and $83 \%$ ). However, diabetic patients with homoglobin (Hb) Alc $\geq 7.0 \%$ showed lower specificity in comparison with those having $\mathrm{HbAlc}<7.0 \%$ (64 vs 88\%; $\mathrm{p}=0.045$ ); however, sensitivities were similar ( $83 \mathrm{vs}$ $83 \%$; $\mathrm{p}=\mathrm{NS}$ ).

Conclusions The cut-off value of 0.75 for FFR can detect myocardial ischemia in diabetic patients, although the adequacy of glycemic control should be taken into consideration when assessing the FFR measurements. (Circ J 2004; 68: 993-998)
\end{abstract}

Key Words: Coronary artery disease; Coronary circulation; Diabetes mellitus; Fractional flow reserve; Thallium myocardial imaging

$\mathbf{T}$ he development of a pressure wire that enables measurement of the pressure gradient across a coronary stenosis has facilitated the use of the myocardial fractional flow reserve (FFR) as a simple, pressure-derived index of the functional severity of the stenosis ${ }^{1-7}$ In theory, there must be maximal arteriolar vasodilatation, resulting in minimal myocardial resistance in a given arterial territory, for FFR to apply as a physiologic index of coronary artery stenosis. Therefore, an important theoretical exception for FFR measurement is the presence of diabetes mellitus (DM) because of the associated functional and/or structural abnormalities in the coronary microvasculature - $^{-10}$ The prevalence of DM in patients with coronary artery disease (CAD) is increasing ${ }^{11}$ so the potential for wider application of FFR measurement as a physiologic assessment of coronary artery stenosis should be tested. Accordingly, the present study evaluated the applicability of FFR in the actual clinical setting, using a heterogeneous group of 245 patients that included 96 with DM.

(Received May 17, 2004; revised manuscript received August 2, 2004; accepted August 19, 2004)

Second Department of Internal Medicine, Tokyo Medical University, Shinjuku-ku, Tokyo, Japan

Mailing address: Hidefumi Yanagisawa, MD, Second Department of Internal Medicine, Tokyo Medical University, 6-7-1 Nishi-Shinjuku, Shinjuku-ku, Tokyo 160-0023, Japan

\section{Methods}

Subjects

We investigated 304 coronary lesions in 245 consecutive patients (206 men, 39 women; mean age $62 \pm 9$ years) who underwent intracoronary pressure measurement in the catheterization laboratory between February 1997 and December 2002, because of angiographic results of intermediate coronary lesions, and who also underwent stress thallium-201 $\left.{ }^{201} \mathrm{Tl}\right)$ single-photon emission computed tomography (SPECT) for suspected CAD. Patients with a history of acute myocardial infarction, unstable angina or revascularization within 1 month prior to the study were excluded. Written informed consent was obtained from all the participants. Of the 245 patients, 133 had angina pectoris and 112 had a previous myocardial infarction (MI) (106 cases of first MI, 6 cases of repeat MI; Q-wave MI in 82 and non-Q-wave MI in 30); 58 patients had undergone intracoronary thrombolysis or primary coronary angioplasty in the acute phase of MI. Of all patients, 62 patients had multi-vessel disease and 183 had single-vessel disease: significant lesions in 133 and insignificant lesions in 50. With regard to coronary risk factors, 159 patients $(65 \%)$ had hypertension, $150(61 \%)$ had hypercholesterolemia, and $150(61 \%)$ were current smokers. DM was diagnosed based on the criteria defined by the Japanese Diabetes Society 12 and 96 patients (39\%) were positive. In addition, the adequacy of glycemic control was assessed by hemo- 


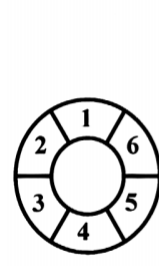

Distal
Short Axis

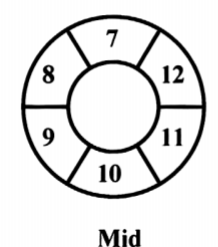

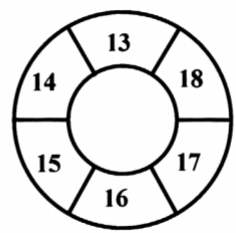

Basal
Vertical Long Axis

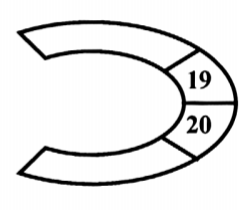

Fig 1. Assigning the myocardial segments for scoring of the SPECT images.

$$
F F R=\frac{P d-P v}{P a-P v} \fallingdotseq \frac{P d}{P a}
$$

Baseline

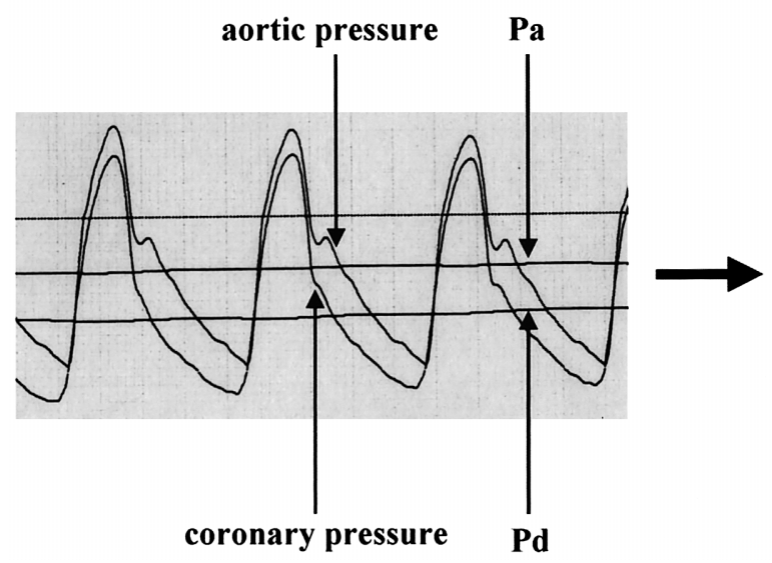

Hyperemia

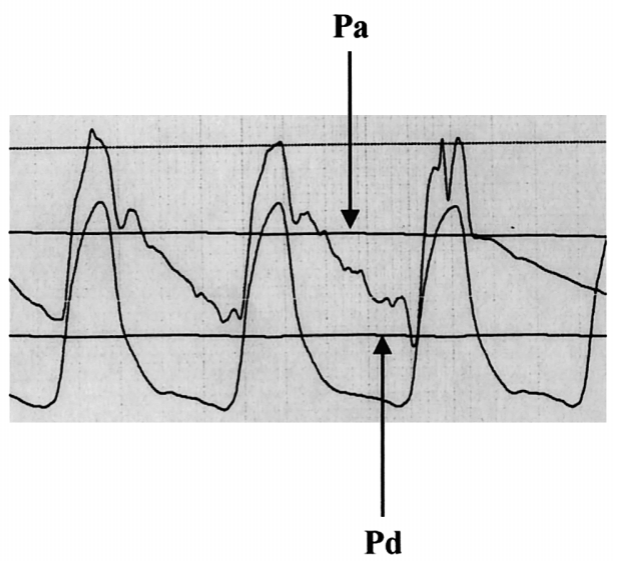

Fig 2. Measurement of fractional flow reserve. Mean coronary pressure is lower than aortic pressure in the site distal to the stenotic lesion at baseline. During hyperemia, there ias a further reduction in the distal coronary artery pressure and FFR is calculated by the formula shown. Pa, mean aortic pressure as measured at the coronary ostium during maximal hyperemia; $\mathrm{Pd}$, mean distal coronary pressure during maximal hyperemia; $\mathrm{Pv}$, mean central venous pressure.

globin (Hb) Alc using chromatographic assay, and diabetic nephropathy was considered to be present if there was proteinuria.

\section{Stress ${ }^{201}$ Tl Myocardial Scintigraphy}

Stress $201 \mathrm{Tl}$ myocardial scintigraphy was performed within 3 months of cardiac catheterization in all cases. The mean time interval between scintigraphy and catheterization was $30 \pm 28$ days. Of the total group, 188 patients underwent exercise ${ }^{201} \mathrm{Tl}$ myocardial scintigraphy on a bicycle ergometer in the sitting position at an initial workload of $25 \mathrm{~W}$ or $50 \mathrm{~W}$, and increments of $25 \mathrm{~W}$ every 3 min!3,14 When the submaximal heart rate was attained, or when the patient developed typical chest pain, ST segment elevation or depression of $1 \mathrm{~mm}$ or more, lower limb fatigue, or severe arrhythmia, $111 \mathrm{MBq}$ of thallium chloride was administered intravenously. Exercise was continued for another minute after the injection. The initial imaging scans were acquired $5 \mathrm{~min}$ after the end of the exercise.

The remaining 57 patients underwent pharmacologic stress SPECT $\geq 15 \mathrm{~h}$ after the cessation of cardioactive medication. Adenosine triphosphate disodium $(0.16 \mathrm{mg} / \mathrm{kg}$ per min) was administered intravenously for $5 \mathrm{~min}$ and 3 min later, $111 \mathrm{MBq}$ of thallium chloride was injected intravenously! ${ }^{15}$ Scintigraphic scanning was commenced within 5 min of ceasing the pharmacologic test. In both of the stress scintigraphy procedures, delayed images were obtained after $4 \mathrm{~h}$ in all patients.
A digital gamma camera equipped with a low-energy high-resolution parallel multi-hole collimator (Prism 2000 XP, Picker; Cleveland, OH, USA) was rotated over a $180^{\circ}$ arc. The SPECT images were processed by an image data processor (Odyssey VP, Picker) using a Butterworth filter (with a cutoff value of 0.25 and an order of 8) and a ramp filter. According to a method reported elsewhere ${ }^{16}$ each SPECT image was divided into 20 segments, with segments $1-3,7-9,13-14$ and 19-20 corresponding to the areas perfused by the left anterior descending coronary artery (LAD), segments 4, 10 and 15-16 corresponding to the areas perfused by the right coronary artery (RCA), and segments 5-6, 11-12 and 17-18 corresponding to the areas perfused by the left circumflex coronary artery (LCX) (Fig 1). The accumulation of radioisotope in the myocardium was visually evaluated by 3 cardiologists using a 5-grade scale: 0 (normal), 1 (slight reduction of uptake), 2 (moderate reduction of uptake), 3 (severe reduction of uptake) or 4 (no radioactive uptake). Disagreements were resolved by consensus. The sum of the scores for the initial image was defined as the summed stress score, whereas that for the delayed image was the summed rest score. The difference between the 2 scores was defined as the summed difference score ${ }^{17}$ In addition, the radioactivity scores in each area perfused by the different coronary arteries were defined as the regional stress score, regional rest score and regional difference score, and these scores were divided by the number of segments involved, to yield the average 
regional stress score, rest score and difference score ${ }^{18}$ In the coronary territory where FFR was measured, if the regional difference score was $\geq 1$, myocardial ischemia was considered to be present.

\section{Coronary Angiography and FFR}

Multi-directional coronary angiography was performed using the Judkin's technique in all patients. Luminal diameter narrowing of $\geq 75 \%$ was considered to represent significant stenosis, in accordance with the American Heart Association classification. ${ }^{19}$ In all patients, intracoronary pressure was measured for the vessels that were angiographically suspected of causing myocardial ischemia. A 0.014 -inch guidewire with a mounted pressure sensor (PressureWire ${ }^{\mathrm{TM}}$, Radi Medical Systems; Uppsala, Sweden) was placed across the lesion. To induce a maximal hyperemic vascular response, $8 \mathrm{mg}$ and $12 \mathrm{mg}$ of the papaverine hydrochloride, as a vasodilator of resistance vessels, was injected into the LCA and RCA, respectively. Under conditions of maximal hyperemia, the pressure distal to the stenosis at the guidewire and the pressure proximal to the stenosis at the tip of the catheter were measured, and the calculated gradient ratio was expressed as the FFR (Fig 2)!,20

\section{Statistical Analysis}

Data are generally expressed as mean \pm SD. Comparison between the means of the continuous variables was performed using the Student's t-test. Contingency tables were analyzed using the chi-squared test, and in addition, Fisher's test where appropriate. To determine the best cutoff value of FFR for detecting myocardial ischemia, a receiver-operating characteristic curve (ROC) analysis was performed. A value of $\mathrm{p}<0.05$ was considered as indicative of significant difference. Computation was performed using the SPSS software (version 11.0 for Windows; SPSS Inc, Chicago, IL, USA).
Table 1 Comparison of the Baseline Characteristics of the Patients With and Without Diabetes

\begin{tabular}{lccc}
\hline \hline & $\begin{array}{c}D M(+) \\
(n=96)\end{array}$ & $\begin{array}{c}D M(-) \\
(n=149)\end{array}$ & p value \\
\hline $\begin{array}{l}\text { Age (years) } \\
\text { M/F }\end{array}$ & $62 \pm 8$ & $62 \pm 9$ & $N S$ \\
Coronary risk factors & $81 / 15$ & $125 / 24$ & $N S$ \\
$\quad$ Hypertension & $65(67 \%)$ & $94(63 \%)$ & $N S$ \\
$\quad$ Hypercholesterolemia & $57(59 \%)$ & $93(62 \%)$ & $N S$ \\
$\quad$ Smoking & $51(53 \%)$ & $99(66 \%)$ & 0.037 \\
Family history of CAD & $15(16 \%)$ & $35(24 \%)$ & $N S$ \\
Myocardial infarction & $45(47 \%)$ & $67(45 \%)$ & $N S$ \\
No. of stenotic vessels & & & \\
0 & $11(12 \%)$ & $39(26 \%)$ & $N S$ \\
1 & $56(58 \%)$ & $77(52 \%)$ & \\
2 & $23(24 \%)$ & $26(17 \%)$ & \\
3 & $6(6 \%)$ & $7(5 \%)$ & \\
Ejection fraction (\%) & $60 \pm 12$ & $62 \pm 11$ & $N S$ \\
\hline
\end{tabular}

$C A D$, coronary artery disease; DM, diabetes mellitus; $N S$, statistically not significant.

\section{Results}

\section{Detection of Myocardial Ischemia by FFR}

The clinical characteristics and angiographic findings of the diabetic and nondiabetic patients were compared (Table 1). The prevalence of smokers was lower in the diabetic patient group than in nondiabetic patients, but the prevalence of all other coronary risk factors and the angiographic findings were similar. The mean left ventricular ejection fraction for the whole group was $62 \pm 12 \%$, and $56 \pm 12 \%$ in the 112 patients with a previous MI.

In the patients with a previous MI, the average regional rest score in the MI territories as evaluated by ${ }^{201} \mathrm{Tl}$ SPECT was $1.43 \pm 0.77$. Of 822 scintigraphic segments involved in the MI territories, severe perfusion defects scoring $\geq 3$ were observed in $213(26 \%)$.

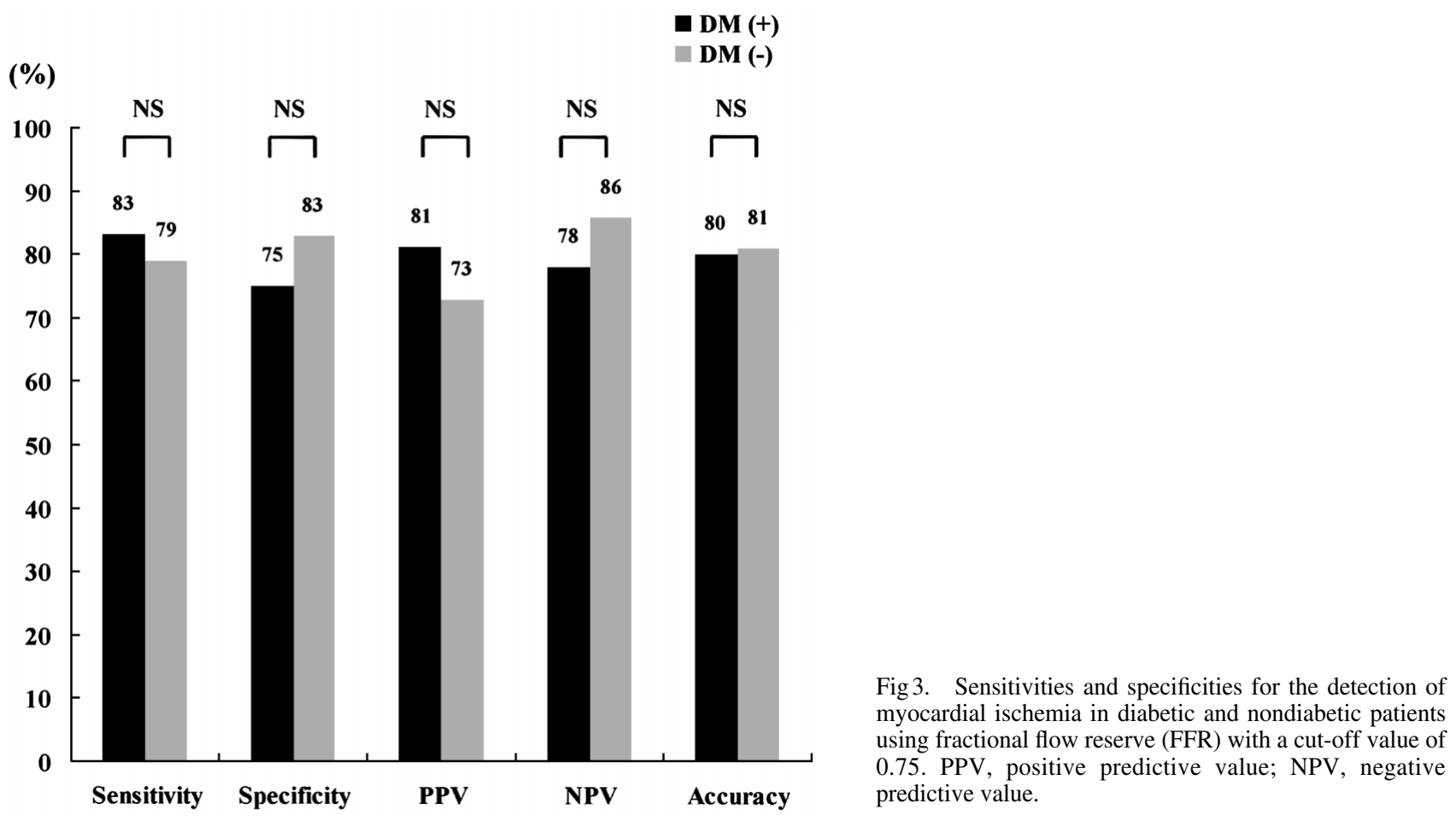




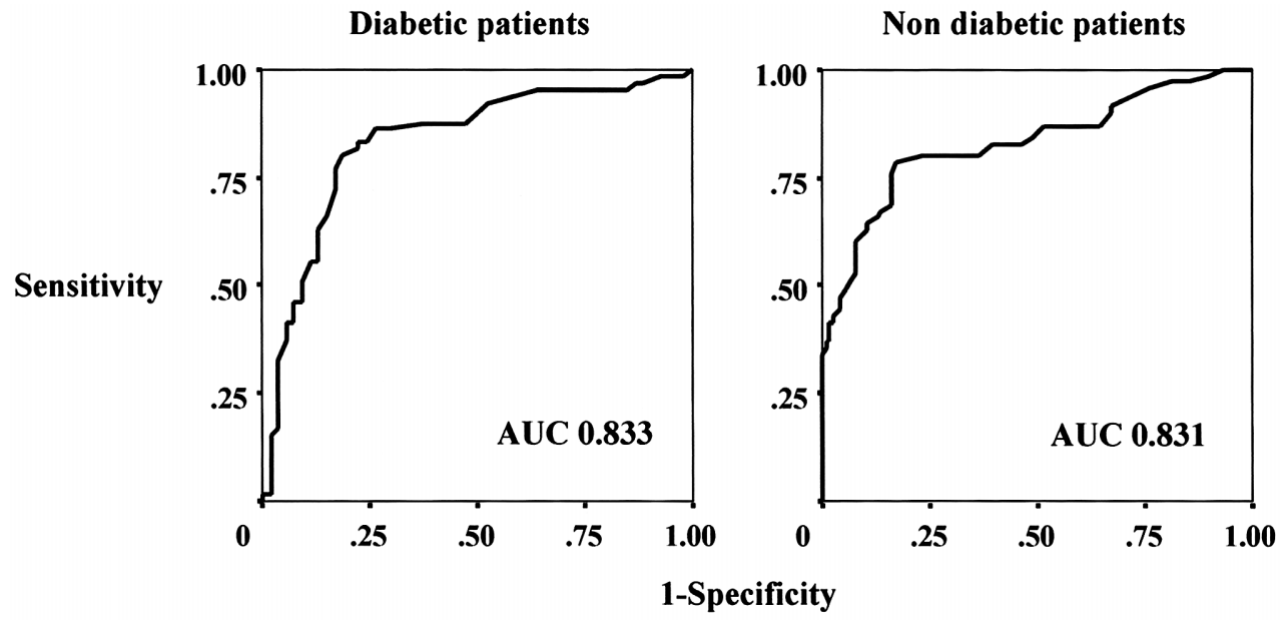

Fig 4. Receiver-operating characteristic curve analysis to determine the best cut-off value for fractional flow reserve (FFR) measurement to detect myocardial ischemia in diabetic and nondiabetic patients. ROC, receiver-operating characteristic curve; AUC, area under the ROC.

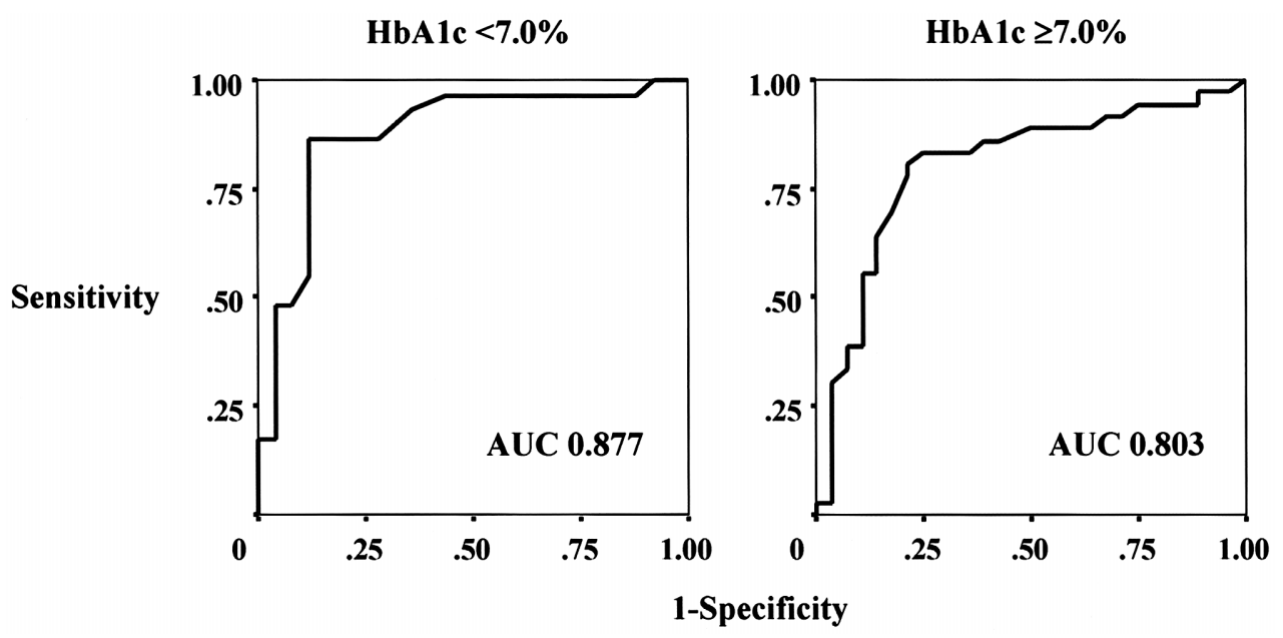

Fig 5. Receiver-operating characteristic curve analysis to determine the best cut-off value for fractional flow reserve (FFR) to detect myocardial ischemia in diabetic patients with $\mathrm{HbA}_{1 c}<7.0 \%$ and in those with $\mathrm{HbA} 1 \mathrm{c} \geq 7.0 \%$.

Among the 304 coronary arteries investigated, FFR was significantly lower in the diabetic patients $(0.68 \pm 0.20 \mathrm{vs}$ $0.74 \pm 0.17$ (nondiabetic); $\mathrm{p}<0.01$ ). The diagnostic performance of using the previously published cut-off value of 0.75 for the detection of myocardial ischemia by FFR in the 96 diabetic patients was $83 \%$ sensitivity and $75 \%$ specificity (Fig 3). A significant correlation between FFR $<0.75$ and stress-induced myocardial ischemia was also observed in the 149 nondiabetic patients (79\% sensitivity, 83\% specificity).

\section{Best Cut-off Value of FFR for Detecting Myocardial Ischemia}

Using a regional difference score $\geq 1$ as the definition of myocardial ischemia, the ROC analysis revealed $83 \%$ sensitivity and $77 \%$ specificity in diabetic patients if the cut-off value of FFR was set at 0.725 . In nondiabetic patients, the ROC analysis showed $79 \%$ sensitivity and $83 \%$ specificity with a cut-off value of 0.745 . In addition, the area under each of these curves (AUC) was similar (0.833 vs $0.831 ; p=N S)$ (Fig 4).
Diagnostic Performance of FFR According to Glycemic Control Status and Diabetic Complications

The mean HbA1c in the 96 diabetic patients was $7.3 \pm$ $1.4 \%$ and based on their glycemic control status, the patients were divided into 2 groups with a cut-off value of $\mathrm{HbA} 1 \mathrm{c}=7.0 \%$. Detecting myocardial ischemia, as demonstrated by ${ }^{201}$ Tl SPECT, using FFR $<0.75$ had lower specificity in the 49 diabetic patients with $\mathrm{HbA} 1 \mathrm{c} \geq 7.0 \%$ than in the 47 with $\mathrm{HbA} 1 \mathrm{c}<7.0 \%$ (64\% vs $88 \%$; $\mathrm{p}=0.045$ ), whereas sensitivity was similar ( 83 vs $83 \% ; \mathrm{p}=\mathrm{NS}$ ). Therefore, specificity in patients with $\mathrm{HbA} 1 \mathrm{c} \geq 7.0 \%$ was lower than in nondiabetic patients (64 vs 83\%; $\mathrm{p}=0.031$ ), whereas specificity in patients with $\mathrm{HbA} 1 \mathrm{c}<7.0 \%$ was similar to nondiabetic patients ( 88 vs $83 \%$; $\mathrm{p}=\mathrm{NS}$ ). By contrast, no significant difference was observed in sensitivity ( 79 vs $83 \%$ vs $83 \%$ ). In patients with $\mathrm{HbA} 1 \mathrm{c} \geq 7.0 \%$, the ROC analysis revealed $81 \%$ sensitivity and $79 \%$ specificity if the cut-off value of FFR was set at 0.690 , where as for $\mathrm{HbA} 1 \mathrm{c}<7.0 \%$, there was $86 \%$ sensitivity and $88 \%$ specificity with a cutoff value of 0.755 . Moreover, the AUC was less in diabetic patients with $\mathrm{HbA} 1 \mathrm{c} \geq 7.0 \%$ than in those with $\mathrm{HbA} 1 \mathrm{c}<7.0 \%$ (0.803 vs 0.877 ) (Fig 5). 
There were 26 patients with diabetic nephropathy and they had higher levels of HbAic compared with those without nephropathy, but it did not reach statistical significance $(7.7 \pm 1.3$ vs $7.2 \pm 1.4 \% ; p=0.109)$. ROC analysis revealed $93 \%$ sensitivity and $68 \%$ specificity in patients with diabetic nephropathy if the cut-off value of FFR was set at 0.725 compared with $82 \%$ sensitivity and $82 \%$ specificity in diabetic patients without nephropathy using a cut-off value of 0.755 . In addition, the 2 AUC were similar $(0.865$ vs 0.840$)$.

\section{Discussion}

The present study demonstrated that pressure-derived FFR was generally reliable in assessing the functional severity of coronary artery stenoses in diabetic patients. Evaluating the detection of myocardial ischemia as demonstrated by ${ }^{201} \mathrm{Tl}$ SPECT, FFR measurement using a previously published cut-off value of $0.75^{20-22}$ in diabetic patients with a mean $\mathrm{HbA1c}$ of $7.3 \%$ showed $83 \%$ sensitivity and $75 \%$ specificity, which was comparable to the $79 \%$ sensitivity and $83 \%$ specificity observed in nondiabetic patients. In addition, ROC analysis performed to clarify whether an FFR of 0.75 was the optimal cut-off value for myocardial ischemia, even in diabetic patients, revealed that the best predictability lay between 0.72 and 0.75 , regardless of the presence or absence of DM. In addition, 112 patients with previous MI were included in this study, because FFR measurements are considered reliable in MI territories with preserved viability, 23,24 and indeed most of the present patients were shown by ${ }^{201}$ TI SPECT to have preserved myocardial viability in the infarcted areas. These results demonstrate that the sensitivity and specificity of FFR with a cut-off value of 0.75 for the detection of myocardial ischemia remain high in a clinical setting that includes diabetic patients, yielding the best possible predictability to be expected in such patients.

There is a wide diversity of presentation for DM with regard to glycemic control and its complications. Subgroup analyses of FFR measurements in the present study population revealed several important findings. First, in diabetic patients with adequate glycemic control (ie, $\mathrm{HbA} 1 \mathrm{c}<7.0 \%)^{25}$ the reliability of the FFR measurements was high, similar to nondiabetic patients. Second, in diabetic patients with inadequate glycemic control (ie, $\mathrm{HbA}_{1 \mathrm{c}} \geq 7.0 \%$ ), not only the cut-off value of 0.75 but also the FFR measurement in itself was considered suboptimal. Third, diabetic nephropathy, one of the most important diabetic complications, may not have a confounding effect on FFR measurements, though further study in a large number of patients is necessary.

In diabetic patients, structural abnormalities in the coronary microcirculation, such as microaneurysm, have been reported $^{6}$ and may contribute to the impaired vasodilator response to potent coronary vasodilators. Functional abnormalities of the coronary microcirculation have been the recent focus ${ }^{7-9}$ and endothelium-dependent and -independent coronary vasodilator functions may be impaired in such patients. 89 However, these observations were derived from diabetic patients with poorly controlled plasma glucose levels $(\mathrm{HbA} 1 \mathrm{c}>8.0 \%)$, and chronic hyperglycemia is regarded as having a key role in the pathogenesis of vascular dysfunction? In the present study, FFR measurements were suboptimal in diabetic patients with $\mathrm{HbA} 1 \mathrm{c}$ $\geq 7.0 \%$, probably because maximal arteriolar vasodilatation was not achieved, whereas it has been found that impaired coronary vasodilator function is almost negligible in diabetic patients whose plasma glucose level is well controlled $(\mathrm{HbA} 1 \mathrm{c}<7.0 \%)^{26}$ a finding that is consistent with the results of the present study. Although Akasaka et al reported that diabetic retinopathy was a marker for coronary microvascular dysfunction, those patients had poorly controlled plasma glucose levels compared with the control group of diabetics without retinopathy (HbAlc: 8.1 vs 6.8\%) ${ }^{26}$ Therefore, retinopathy and also chronic hyperglycemia may be key indicators of an impaired coronary vasodilator response as assessed by intracoronary Doppler measurements. ${ }^{26}$ Those observations, in conjunction with ours, explain the high reliability of FFR measurements in diabetic patients with optimal glycemic control in whom the coronary microvascular dysfunction may be attenuated ${ }^{10,26}$ Caution is necessary, though, when evaluating FFR measurements in diabetic patients with inadequate glycemic control.

To obtain maximal vasodilation, we used a fixed dose of intracoronary papaverine and the suboptimal results of FFR measurement in the diabetic patients whose glycemic control was inadequate, may be partly related to an inadequate response to a standard dose of this drug. ${ }^{27}$ Indeed, Murtagh et al reported that incremental doses of intracoronary adenosine were necessary to ensure maximal hyperemia in a minority of patients ${ }^{28}$ To maximize the clinical utility of FFR measurement, incremental dosing of intracoronary papaverine or adenosine may be needed in diabetic patients, particularly those with poor glycemic control. However, is it worthwhile assessing FFR in diabetic patients with $\mathrm{HbA}_{1 c}>7.0 \%$, other than for unstable angina? ${ }^{29}$ The advantage of FFR measurements is to confirm a decision to perform coronary intervention and accumulating evidence suggests a high rate of restenosis after elective percutaneous coronary intervention in diabetic patients whose glycemic control is inadequate $30-32$ Therefore, an interventional treatment strategy guided by FFR measurements may not have high reliability in this patient group. Whether or not interventional treatment should be postponed until glycemic control is under optimal control in diabetic patients with stable angina requires further investigation.

\section{Acknowledgment}

The authors thank Professor Patrick Barron of Tokyo Medical University International Medical Communication Center for his assessment of the manuscript.

\section{References}

1. De Bruyne B, Pijls NH, Paulus WJ, Vantrimpont PJ, Sys SU, Heyndrickx GR. Transstenotic coronary pressure gradient measurement in humans: In vitro and in vivo evaluation of a new pressure monitoring angioplasty guide wire. J Am Coll Cardiol 1993; 22: 119-126.

2. Pijls NH, van Son JA, Kirkeeide RL, De Bruyne B, Gould KL. Experimental basis of determining maximum coronary, myocardial, and collateral blood flow by pressure measurements for assessing functional stenosis severity before and after percutaneous transluminal coronary angioplasty. Circulation 1993; 87: 1354-1367.

3. Serruys PW, di Mario C, Piek J, Schroeder E, Vrints C, Probst P, et al. Prognostic value of intracoronary flow velocity and diameter stenosis in assessing the short- and long-term outcomes of coronary balloon angioplasty: The DEBATE Study (Doppler Endpoints Balloon Angioplasty Trial Europe). Circulation 1997; 96: 33693377.

4. Heller LI, Cates C, Popma J, Deckelbaum LI, Joye JD, Dahlberg ST, et al. Intracoronary Doppler assessment of moderate coronary artery disease: Comparison with ${ }^{201} \mathrm{Tl}$ imaging and coronary angiography. 
Circulation 1997; 96: 484-490

5. Yanagisawa H, Chikamori T, Tanaka N, Hatano T, Morishima T, Hida S, et al. Correlation between thallium-201 myocardial perfusion defects and the functional severity of coronary artery stenosis as assessed by pressure-derived myocardial fractional flow reserve. Circ J 2002; 66: 1105-1109.

6. Nitenberg A, Valensi P, Sachs R, Dali M, Aptecar E, Attali JR. Impairment of coronary vascular reserve and ACh-induced coronary vasodilation in diabetic patients with angiographically normal coronary arteries and normal left ventricular systolic function. Diabetes 1993; 42: $1017-1025$.

7. Pitkanen OP, Nuutila P, Raitakari OT, Ronnemaa T, Koskinen PJ, Iida $\mathrm{H}$, et al. Coronary flow reserve is reduced in young men with IDDM. Diabetes 1998; 47: 248-254.

8. Nahser PJ Jr, Brown RE, Oskarsson H, Winniford MD, Rossen JD. Maximal coronary flow reserve and metabolic coronary vasodilation in patients with diabetes mellitus. Circulation 1995; 91: 635-640.

9. Di Carli MF, Janisse J, Grunberger G, Ager J. Role of chronic hyperglycemia in the pathogenesis of coronary microvascular dysfunction in diabetes. J Am Coll Cardiol 2003; 41: 1387-1393.

10. Akasaka T, Yoshida K, Hozumi T, Takagi T, Kaji S, Kawamoto T, et al. Retinopathy identifies marked restriction of coronary flow reserve in patients with diabetes mellitus. J Am Coll Cardiol 1997; 30: 935941.

11. Stamler J, Vaccaro O, Neaton JD, Wentworth D. Diabetes, other risk factors, and 12-yr cardiovascular mortality for men screened in the Multiple Risk Factor Intervention Trial. Diabetes Care 1993; 16: 434-444.

12. The Committee of Japan Diabetes Society for the Diagnostic Criteria of Diabetes Mellitus. Report of the committee of Japan Diabetes Society on the classification and diagnostic criteria of diabetes mellitus. J Jpn Diabetes Soc 1999; 42: 385-404 (in Japanese).

13. Yamagishi $\mathrm{H}$, Akioka $\mathrm{K}$, Takagi $\mathrm{M}$, Tanaka A, Takeuchi $\mathrm{K}$, Yoshikawa J, et al. Relation between the kinetics of thallium-201 in myocardial scintigraphy and myocardial metabolism in patients with acute myocardial infarction. Heart 1998; 80: 28-34.

14. Hida S, Chikamori T, Hirayama T, Usui Y, Yanagisawa H, Morishima $\mathrm{T}$, et al. Beneficial effect of coronary artery bypass grafting as assessed by quantitative gated single-photon emission computed tomography. Circ J 2003; 67: 499-504.

15. Miyagawa M, Kumano S, Sekiya M, Watanabe K, Akutzu H, Imachi $\mathrm{T}$, et al. Thallium-201 myocardial tomography with intravenous infusion of adenosine triphosphate in diagnosis of coronary artery disease. J Am Coll Cardiol 1995; 26: 1196-1201.

16. Berman DS, Hachamovitch R, Kiat H, Cohen I, Cabico JA, Wang $\mathrm{FP}$, et al. Incremental value of prognostic testing in patients with known or suspected ischemic heart disease: A basis for optimal utilization of exercise technetium-99m sestamibi myocardial perfusion single-photon emission computed tomography. J Am Coll Cardiol 1995; 26: 639-647.

17. Berman DS, Germano G. Myocardial perfusion single photon approaches. In: Pohost GM, O'Rourke RA, Berman DS, Shah PM, editors. Imaging in cardiovascular disease. Philadelphia: Lippincott Williams \& Wilkins; 2000; 159-194.

18. Hida $\mathrm{S}$, Chikamori $\mathrm{T}$, Usui $\mathrm{Y}$, Yanagisawa $\mathrm{H}$, Morishima $\mathrm{T}$,
Yamashina A. Effect of percutaneous coronary angioplasty on myocardial perfusion, function, and wall thickness as assessed by quantitative gated single-photon emission computed tomography. Am J Cardiol 2003; 91: 591-594.

19. AHA Committee. A reporting system on patients evaluated for coronary artery disease. Circulation 1975; 51: 5-34.

20. Pijls NH, Van Gelder B, Van der Voort P, Peels K, Bracke FA, Bonnier HJ, et al. Fractional flow reserve: A useful index to evaluate the influence of an epicardial coronary stenosis on myocardial blood flow. Circulation 1995; 92: 3183-3193.

21. De Bruyne B, Bartunek J, Sys SU, Heyndrickx GR. Relation between myocardial fractional flow reserve calculated from coronary pressure measurements and exercise-induced myocardial ischemia. Circulation 1995; 92: 39-46.

22. Pijls NH, De Bruyne B, Peels K, Van Der Voort PH, Bonnier HJ, Bartunek J, et al. Measurement of fractional flow reserve to assess the functional severity of coronary-artery stenoses. $N$ Engl J Med 1996; 334: 1703-1708.

23. Usui Y, Chikamori T, Yanagisawa H, Morishima T, Hida S, Tanaka $\mathrm{N}$, et al. Reliability of pressure-derived myocardial fractional flow reserve in assessing coronary artery stenosis in patients with previous myocardial infarction. Am J Cardiol 2003; 92: 699-702.

24. De Bruyne B, Pijls NH, Bartunek J, Kulecki K, Bech JW, De Winter $\mathrm{H}$, et al. Fractional flow reserve in patients with prior myocardial infarction. Circulation 2001; 104: 157-162.

25. UK Prospective Diabetes Study (UKPDS) Group. Intensive bloodglucose control with sulphonylureas or insulin compared with conventional treatment and risk of complications in patients with type 2 diabetes (UKPDS 33). Lancet 1998; 352: 837-853.

26. Takiuchi S, Rakugi H, Masuyama T, Ikegami H, Nishikage T, Shintani M, et al. Hypertension attenuates the efficacy of hypoglycemic therapy for preserving coronary flow reserve in patients with type 2 diabetes. Hypertens Res 2002; 25: 893-900.

27. Wilson RF, White $\mathrm{CW}$. Intracoronary papaverine: An ideal coronary vasodilator for studies of the coronary circulation in conscious humans. Circulation 1986; 73: 444-451.

28. Murtagh B, Higano S, Lennon R, Mathew V, Holmes DR Jr, Lerman A. Role of incremental doses of intracoronary adenosine for fractional flow reserve assessment. Am Heart J 2003; 146: 99-105.

29. Leesar MA, Abdul-Baki T, Akkus NI, Sharma A, Kannan T, Bolli R. Use of fractional flow reserve versus stress perfusion scintigraphy after unstable angina. J Am Coll Cardiol 2003; 41: 1114-1121.

30. Asakura Y, Suzuki M, Nonogi H, Haze K, Sato A, Inada H, et al. Restenosis after percutaneous transluminal coronary angioplasty in patients with non-insulin-dependent diabetes mellitus (NIDDM). $J$ Cardiovasc Risk 1998; 5: 331-334.

31. Mazeika P, Prasad N, Bui S, Seidelin PH. Predictors of angiographic restenosis after coronary intervention in patients with diabetes mellitus. Am Heart J 2003; 145: 1013-1021.

32. Corpus RA, George PB, House JA, Dixon SR, Ajluni SC, Devlin $\mathrm{WH}$, et al. Optimal glycemic control is associated with a lower rate of target vessel revascularization in treated type II diabetic patients undergoing elective percutaneous coronary intervention. $J$ Am Coll Cardiol 2004; 43: 8-14. 